\title{
Characterisation of hydraulically-active fractures in a fractured granite aquifer
}

\author{
Hang Bok Lee' and Byung-Woo Kim²* \\ 'Underground Space Department, Korea Institute of Geosciences and Mineral Resources, Daejeon 305-350, Republic of Korea \\ ${ }^{2}$ Radioactive Waste Disposal Research Division, Korea Atomic Energy Research Institute, Daejeon 305-353, Republic of Korea
}

\begin{abstract}
In this study, the practical usefulness and fundamental applicability of a self-potential (SP) method for identifying the hydraulically-active fractures were evaluated by a comparison of SP methods with other geophysical logging methods and hydraulic tests. Potentially permeable fractures intersecting a shallow, 10 - $\mathrm{m}$ borehole were first identified using conventional geophysical methods such as acoustic borehole televiewer imaging and temperature, electrical conductivity and gamma-gamma logs. These results were then compared to results of analysis using the SP method. Constant pressure injection and recovery tests were conducted for verification of the hydraulic properties of the fractures identified by various logging methods. The acoustic borehole televiewer and gamma-gamma logs detected the openings or weathering zones associated with fractures intersecting the borehole, but they could not prove that groundwater was flowing through the detected fractures. The temperature and fluid-column electrical conductivity logs were unable to detect the fractured zones where groundwater in the borehole flows out to the surrounding rock aquifers. Comparison of results from the different methods tested showed that the most effective correlation between logs and the distribution of hydraulic conductivity was given by the SP signals, and that SP logging can accurately indicate the location of hydraulically-active permeable fractures. Based on these results, the SP method is recommended for determining the location of hydraulically-active fractures rather than other conventional geophysical logs. This self-potential method can be effectively applied in the initial stage of a site investigation to select the optimal site location or to evaluate the hydrogeological properties of fractures in underground exploration studies, such as those related geothermal reservoir evaluation and radioactive waste disposal.
\end{abstract}

Keywords: self-potential method, hydraulically-conductive fractures, constant pressure injection and recovery tests, underground structure

\section{INTRODUCTION}

Fractured rock aquifers are currently regarded as of particular interest and an important issue because of their usefulness related to underground water supply, energy storage, and radioactive waste disposal. They are generally characterised by strong heterogeneity due to the inherently large contrasts in hydraulic properties between the highly permeable fractures and the surrounding rock matrix of generally negligible permeability. The sustainable use of groundwater in fractured rock aquifers requires a detailed knowledge of their hydraulic properties, which makes the detection and hydraulic characterisation of permeable fractures an ever more important task (Lemieux et al., 2006).

There are many conventional geophysical methods for the detection of individual fractures in situ, such as temperature, calliper, gamma-gamma and fluid electrical conductivity logs (Tittman, 1965; Malcolm, 1984; Hearst et al., 2000). However, these borehole-logging methods, which are generally used for identifying a relatively large-scale open fractured or weathered zone, have limitations for identifying the small-scale permeable fractures serving as pathways for groundwater flow. The acoustic borehole televiewer, a more visually-advanced logging technique, provides high-resolution images of the location and dip of fractures within a borehole (Keys, 1990), but still cannot

\footnotetext{
To whom all correspondence should be addressed

+82-42-868-8290. e-mail: bwkim@kaeri.re.kr Received 22 July 2014; accepted in revised form 7 January 2015.
}

provide any information with regard to the hydraulic activity of the fractures.

The limitation of traditional logging methods in determining the hydraulic properties of fractures can be potentially improved by self-potential (SP) measurements that are closely related to the movement of fluids within fractures (Ogilvy et al., 2969; Rozycki et al., 2006). Self-potential (SP) measurements have long been used to detect the presence of leakage through dams and dikes that pose a potential hazard to these structures (Al-Saigh et al., 1994; Panthulu et al., 2001; Song et al., 2005; Rozycki et al., 2006; Moore et al., 2011), to characterise geothermal resources (Anderson and Johnson, 1973; Corwin and Hoover, 1979; Ishido and Pritchett, 1999), to determine hydraulic properties of the shallow subsurface (Rizzo et al., 2004) and to evaluate groundwater movement and flow paths (Schiavone and Quarto, 1984; Fournier, 1989; Jardani et al., 2006).

A special advantage of a self-potential technique in fractured rock aquifers is that it is directly sensitive to the inflow or outflow through fractures and can respond to very weak fluid movements. Thus, the self-potential measurement has been considered an effective alternative to detect and characterise hydraulically-active fractures (Hunt and Worthington, 2000; Sharma and Baranwal, 2005; Suski et al., 2008). However, there are limited studies demonstrating the practical application of the self-potential method to precise characterisation of smallscale permeable fractures that have been verified by direct comparison with hydraulic tests.

The aim of this study is to evaluate the effectiveness and applicability of the self-potential method for detecting and characterising the hydraulically-active fractures at a shallow 


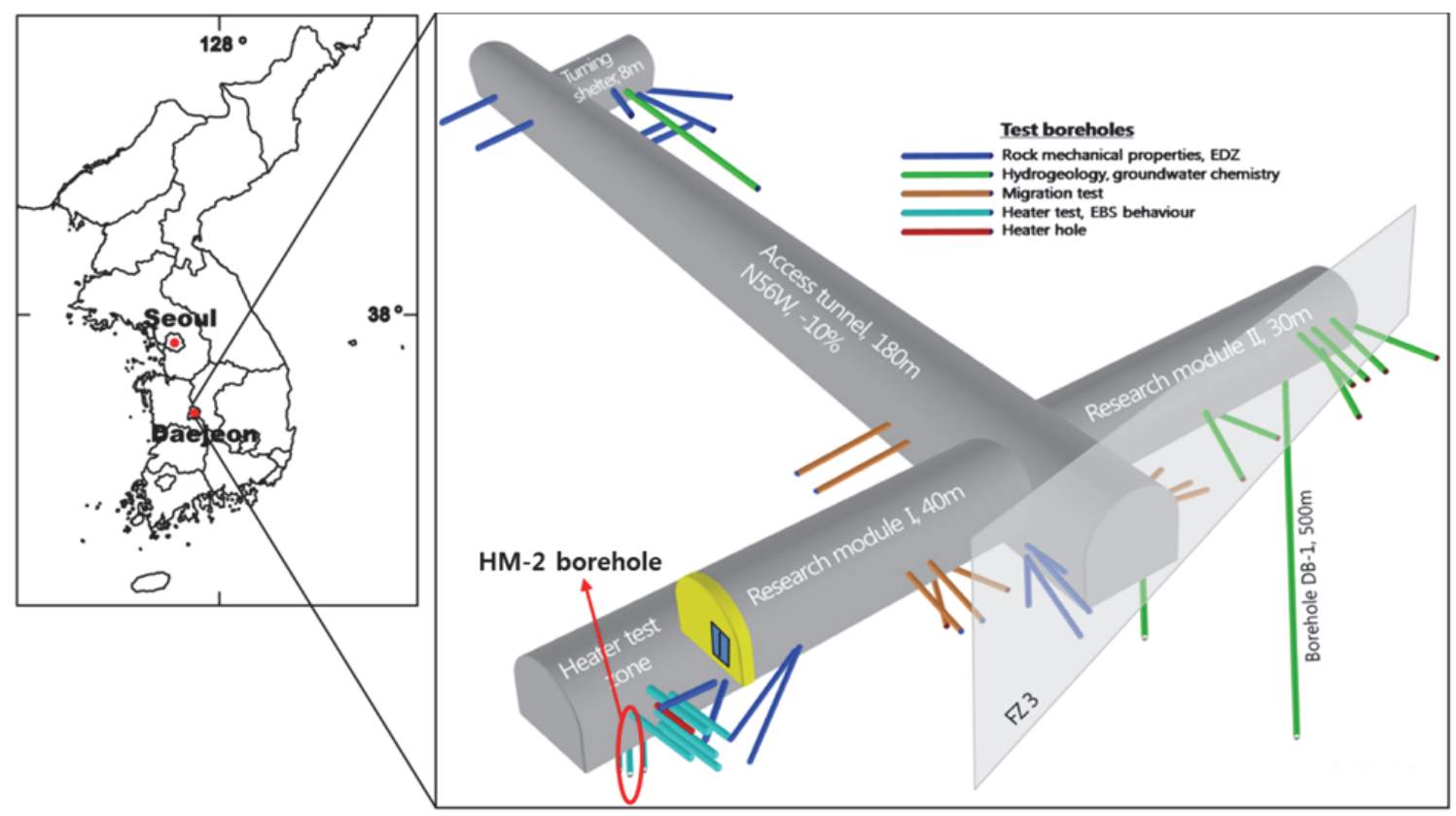

Figure 1

Layout of the URT and the location of the test borehole, $\mathrm{HM}-2$

borehole in fractured rock aquifers. The SP measurements are compared to conventional geophysical well-logging methods such as acoustic borehole televiewer, temperature, fluid electrical conductivity, and gamma-gamma logs obtained from the same borehole. The observed fractures showed quite a difference in their number and location among the various conventional geophysical methods. Then, the hydraulic tests, including constant pressure injection and recovery tests, were conducted in several packed-off intervals along the borehole and were used to verify the hydraulic properties of fractures identified by geophysical loggings.

\section{STUDY AREA}

The test borehole is located in the URT (Underground Research Tunnel) built at a mountainous area, Daejeon city, Korea (Fig. 1). URT is a small-scale underground research facility for the validation of the Korean reference HLW disposal system. The utilisation of radioactive material in URT is not allowed. URT has a total length of $255 \mathrm{~m}$ with a $180 \mathrm{~m}$ long access tunnel and 2 research modules with a total length of $75 \mathrm{~m}$. The maximum depth of the tunnel is $90-100 \mathrm{~m}$ from the peak of a mountain located above the site. A downward tunnel slope of $10 \%$ was applied to achieve the required minimum depth for the URL. Biotite and schistose granite are the major rock types of URT and andesite dikes are encountered in some locations.

Figure 1 shows the layout of URT and its installed boreholes. Heterogeneous gravel and silty-sand compose the first layer of the fractured rocks at the test site, which extends from the tunnel floor to a depth of $0.3 \mathrm{~m}$. Under the mixed layer, the hard rock is continuously distributed down to $250 \mathrm{~m}$. Several boreholes $10 \sim 30 \mathrm{~m}$ in depth were previously installed for the heater/migration tests, excavation damaged zone characterisation, and hydrogeological/geochemical evaluation. A $10 \mathrm{~m}$ shallow borehole named HM-2 was vertically drilled at the end of research module I to investigate the thermal-hydrologicalmechanical behaviour characteristics and the field applicability of an engineered barrier system, which was used for this study. The borehole was not screened, and its diameters were $0.076 \mathrm{~m}$ in the section from 0 to $9 \mathrm{~m}$ depth below the top of the casing (TOC) and $0.06 \mathrm{~m}$ in the remainder. The HM-2 borehole was an artesian well and its static water level was approximately $2 \mathrm{~m}$ above the tunnel floor.

\section{GEOPHYSICAL LOGGING METHODS AND HYDRAULIC TEST PROCEDURES}

\section{Conventional geophysical loggings}

First, geophysical logs such as acoustic borehole televiewer (BHTV), temperature, electrical conductivity, and gammagamma logs were run to identify the fractures crossing the HM-2 borehole. In BHTV logging, the acoustic image of the borehole wall is produced by transmitting and receiving highfrequency acoustic pulses from a rotating transducer. The amplitude and travel time of the reflected acoustic signal are measured as separate images. BHTV log images provide information on the location, strike and dip of the fractures within a borehole (Keys, 1990; Williams and Johnson, 2004). Because the BHTV is not affected by the clarity of the borehole water, it can be used even in a borehole that contains muddy water and has unclean walls. The gamma-gamma logging tool consists of a radioactive source and gamma ray detector. After the emitted gamma rays from a source are attenuated and scattered in the borehole and surrounding rocks, the detector measures the intensity of the back-scattered gamma rays, which is used to estimate the density of geologic formation surrounding the borehole (Tittman and Whal, 1965) The location of fractured zones is indicated wherever the density log indicates small cavities of borehole wall or the presence of weathered rock. The gamma-gamma logging can only be applied in an open borehole because the presence of casing and cement would prevent contact with the rock itself. 


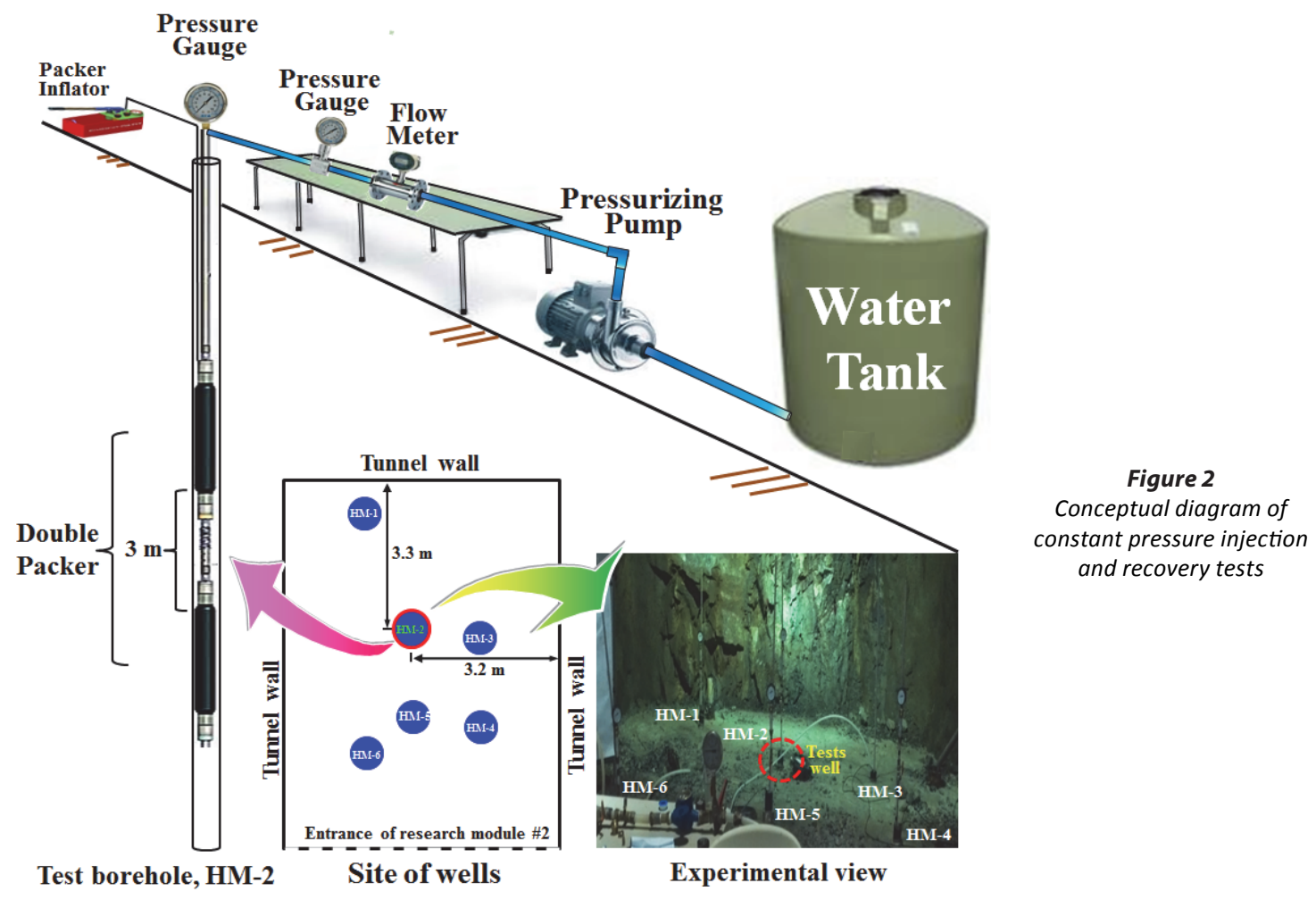

The temperature and fluid-column electrical conductivity (EC) logging that can provide information on the movement of groundwater through the borehole was performed to estimate the permeable fractures. Temperature can identify the location of fractures crossing the borehole. In boreholes with no vertical flow, the temperature of the borehole water generally increases with depth, as a function of the geothermal gradient in the surrounding rocks. However, if the borehole meets a waterconductive or fractured zone, the temperature can suddenly depart from the steady geothermal gradient. In this study, the temperature of the groundwater was logged along the HM-2 borehole, and the location of the rock fractures was identified by checking the temperature differential log (temperature differences between adjacent measurement stations). The electrical conductivity logging related to the dissolved-solids concentration of water can also be used to detect a permeable fracture or fractured zones, because fluid conductivity may change abruptly at the locations where water is flowing into the borehole (Williams and Conger, 1990). In our experiment, the abrupt changes in electrical conductivity along the HM-2 borehole were also used to identify permeable fractures.

\section{Self-potential method}

Self-potential (SP) logging is a passive-type geophysical method. This method uses variations of a naturally-occurring potential-field distributed in the subsurface. The processes that create the potentials are mainly electrochemical reactions and electokinetics due to the motion of underground electrolytic fluid through a saturated porous medium (Ishido and Mizutani, 1981; Pride, 1994; Revil et al., 1999, 2003). When groundwater flows through a porous medium, the drag of the excess charge found in the vicinity of the water-mineral interface can produce an electrical potential called the streaming potential (Sill, 1983; Birch, 1998; Doussan et al., 2002). In a water-filled well, the streaming potential may be observed at locations where water is moving into or out of the borehole. These permeable locations are typically indicated by abrupt variations of SP signal in an otherwise smooth curve. In this study, we measured the variation of the self-potential signal along the vertical extent of the HM-2 borehole, and we used this data to determine the presence of hydraulically-active fractures.

The field equipment used for SP measurements is simple to run and inexpensive. The equipment consists of a traveling electrode in the borehole connected to a reference electrode and a laptop computer connected to a multivolt meter for obtaining and storing the SP signal. The reference electrode is installed outside of the test borehole where the SP values are expected to remain steady. The traveling electrode is usually inserted in a probe that performs other geophysical measurements on the same logging run. When the traveling electrode moves vertically along the borehole, potential changes in the millivolt range are recorded and displayed graphically. An anomaly in an SP signal can be associated with temperature, quantity of clay present, man-made structures such as steel casing, and the electrochemical property of the water as well as the subsurface water movement. Therefore, great care should be taken in acquiring and interpreting the SP data by considering the abovementioned factors along with potential sources of artificial noise.

\section{Constant pressure injection and recovery test}

Constant pressure injection and recovery tests were conducted at the HM-2 borehole using a double packer system composed of hydraulically inflated rubber packers. In this study, constant injection pressures were applied into each test section and the flow rates were recorded for estimating the hydraulic conductivity $(K)$, which was used to evaluate the hydraulic activity of the fractures located in the test zone. A schematic view of the experimental setup using a double packer is shown in Fig. 2. Test intervals were divided into 3 sections below the steel 
TABLE 1

Hydraulic conductivity from constant pressure injection and recovery tests

\begin{tabular}{|l|c|c|c|c|c|l|}
\hline $\begin{array}{l}\text { Test interval } \\
\text { from TOC }[\mathrm{m}]\end{array}$ & $\begin{array}{c}\text { Initial } \\
\text { Pressure }(\text { bar) }\end{array}$ & $\begin{array}{c}\text { Injection } \\
\text { Pressure }(\text { bar) }\end{array}$ & $\begin{array}{c}\text { Hydraulic } \\
\text { Head }(\mathrm{m})\end{array}$ & $\begin{array}{c}\mathrm{K}(\mathrm{m} / \mathrm{s}), \\
\text { Moye model }\end{array}$ & $\begin{array}{c}\mathrm{K}(\mathrm{m} / \mathrm{s}), \\
\text { Horner model }\end{array}$ & $\begin{array}{l}\text { Explanatory } \\
\text { note }\end{array}$ \\
\hline $1.0 \sim 4.0$ & 1.10 & 2.05 & 2.4 & Immeasurable & $3.14 \times 10^{-11}$ & Very low permeability \\
\hline $4.0 \sim 7.0$ & 1.10 & 3.00 & 11.8 & $5.92 \times 10^{-7}$ & $6.10 \times 10^{-7}$ & \\
\hline $7.0 \sim 10.0$ & 0.10 & 2.05 & 8.6 & $4.27 \times 10^{-8}$ & $2.34 \times 10^{-8}$ & \\
\hline
\end{tabular}

casing: $1.0 \sim 4.0 \mathrm{~m}, 4.0 \sim 7.0 \mathrm{~m}$, and $7.0 \sim 10.0 \mathrm{~m}$. The pressure in the test interval was instantaneously increased from the initial pressure to the assigned pressure by first injecting pressurised water using a constant pressure injection pump, and then keeping the increased pressure constant. The outflow rate was greatest in the beginning and gradually converged to a certain steady value, which was measured using a flow meter and pressure gauge. Calculation of the hydraulic properties of a rock mass from the results of the injection tests are generally based on the steady-state flow rates. Because it may take several hours to fully establish a steady-state flow, it can be necessary to curtail the tests before reaching the steady-state flow conditions (normally about $1 \mathrm{~h}$ ) in order to speed up the accumulation of hydraulic data. In this study, the flow rate recorded after $1 \mathrm{~h}$ was generally higher than the steady-state flow rate, but not significantly. The outflow rate was measured every $5 \mathrm{~s}$ when the elapsed time was less than $1 \mathrm{~h}$. After the elapsed time of $1 \mathrm{~h}$, it was measured every $30 \mathrm{~min}$. In each case the hydraulic head was measured every $3 \mathrm{~s}$ during the entire test.

The Moye model was used to analyse the constant pressure injection tests.

$$
K=\frac{q}{l H_{0}}\left[\frac{1}{2 \pi}\left(1+\ln \left(\frac{l}{2 r_{w}}\right)\right]\right.
$$

where:

$q$ is the injection rate

$l$ is the length of test section

$H_{0}$ is the injection pressure

$r_{w}$ is the well radius.

Equation (1) assumes that a radial flow occurs near the borehole of the test section and is converted into a spherical flow beyond a distance from the borehole equalling half of the test interval length $(l)$. After the measured outflow converged on a steady value, the recovery test began by stopping the groundwater outflow and letting the hydraulic head return to the initial head, which was analysed using the Horner model in this study.

$$
K=\frac{0.183 Q_{p} P_{w} g}{\Delta\left(d p^{\prime}\right) l}
$$

where:

$Q_{p}$ is the injection rate at the injection end-point

$\Delta d p$ ' is the pressure change during one log-period

$P_{w}$ is the water density

$g$ is the gravity acceleration

$l$ is the length of the test section.

A summary of the results of constant pressure injection and recovery tests carried out in an HM-2 borehole is given in Table 1. The imposed differences between the initial and assigned water pressures in this study are commonly thought to be reasonable in hydraulic tests performed in rock aquifers (Beauheim et al., 2004). Initial and assigned water pressures refer to the measured zone hydraulic head values and the heads imposed by the hydraulic tests to induce flow, respectively.

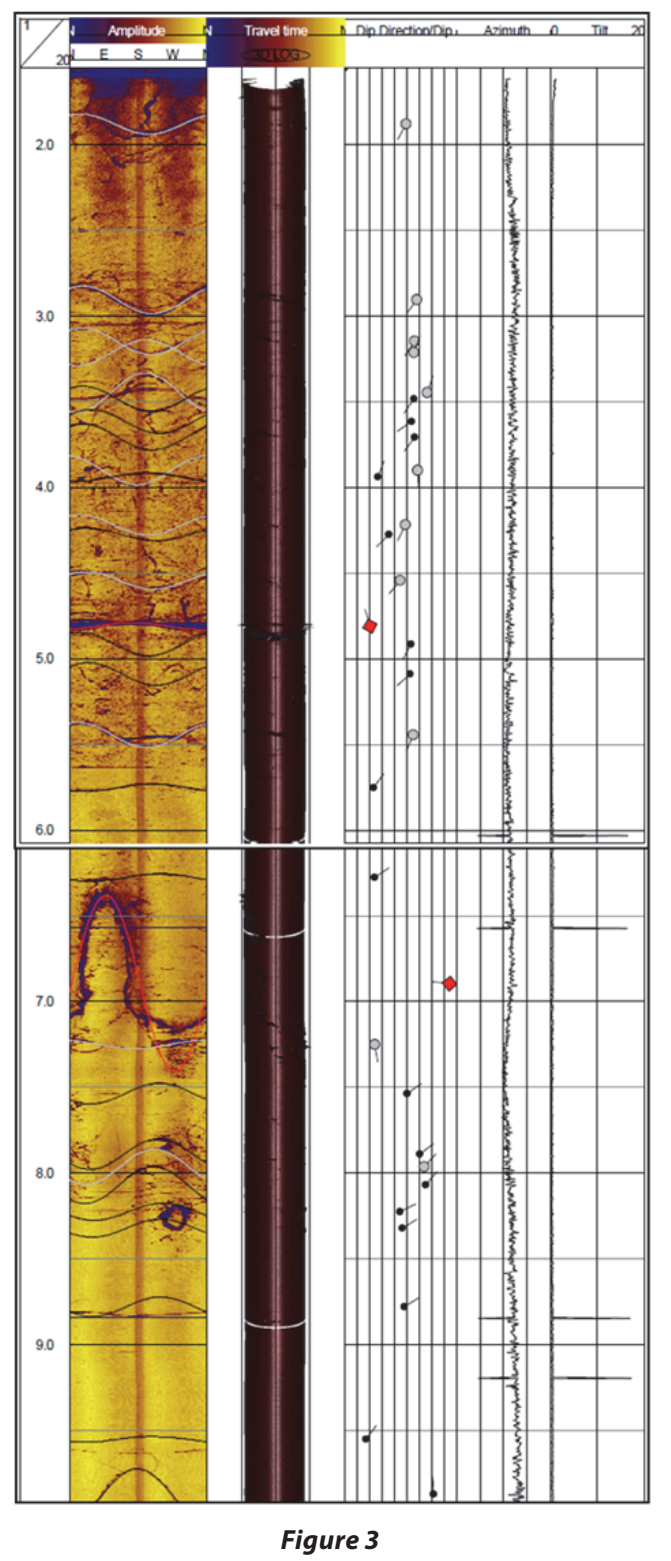

Acoustic borehole televiewer (BHTV) image of HM-2 borehole

\section{RESULTS}

\section{Identification of the fractured zones with various log measurements}

The fractures along the HM-2 borehole were initially identified using an acoustic borehole televiewer (BHTV) as shown in Fig. 3, which indicated that the rock penetrated by the borehole is moderately fractured and that there are 2 distinct zones of highly fractured rock. The BHTV logs detected a total of 31 fractures crossing the borehole (Fig. 3). 17 fractures were 


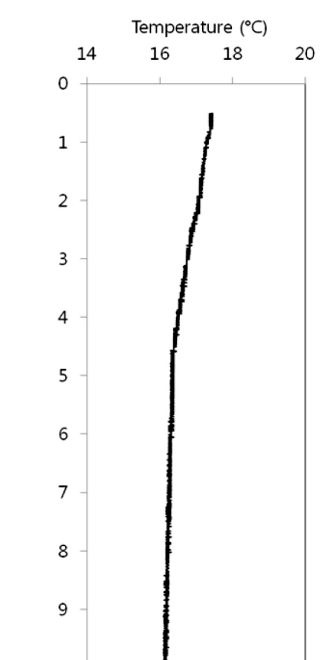

(a)

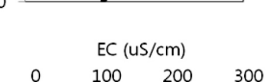

(b)

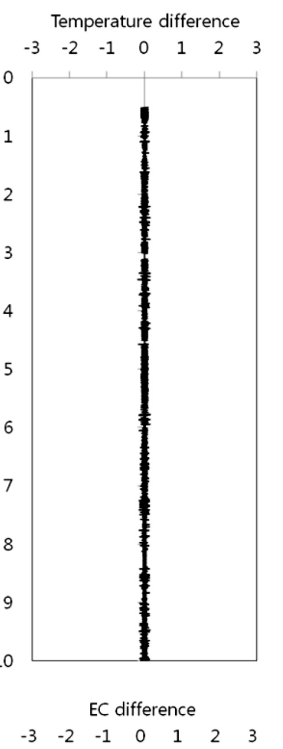

(c)

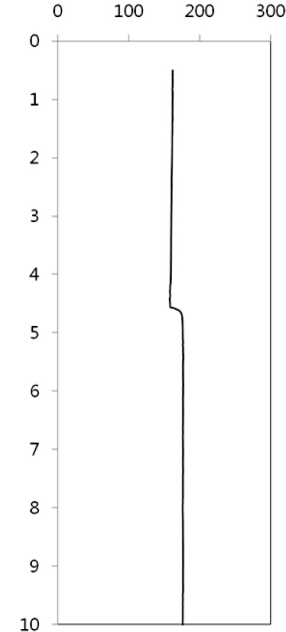

Figure 4

(a) Results of the groundwater temperature logging along $\mathrm{HM}-2$ borehole. (b) Temperature difference. (c) Results of the EC logging along HM-2 borehole. (d) EC difference.

observed as closed fractures, 12 fractures were identified as partially open fractures, and 2 major fractures were shown as wide and permeable fractures. The assumption here is that 'partial' means that the fracture appears wide enough to be open over only part of the extent of the intersection with the borehole. From this result, 5 zones at 1.9 m, 2.9-3.4 m, 3.9-4.8 $\mathrm{m}, 5.4 \mathrm{~m}$, and $6.9 \mathrm{~m}$ in depth below the top of the casing (TOC) were determined as possibly permeable fracture zones. The BHTV method can provide a qualitative indication of the fracture size because the width of the apparent aperture increases as the BHTV image of the fracture becomes darker and wider. It is generally assumed (Keys, 1990) that larger apparent fracture apertures on BHTV images are more likely to be permeable. However, the hydraulic activity of such fractures is not absolutely connected to apparent fracture size because there are many large-scale isolated fractures that cannot act as a conductive pathway of the groundwater. Therefore, it is difficult to determine the hydraulic activity of the fractures detected using only BHTV image logging without the verification provided by precise hydraulic tests.

Figure 4a shows the results of the groundwater temperature logging in the HM-2 borehole. The temperature gradually

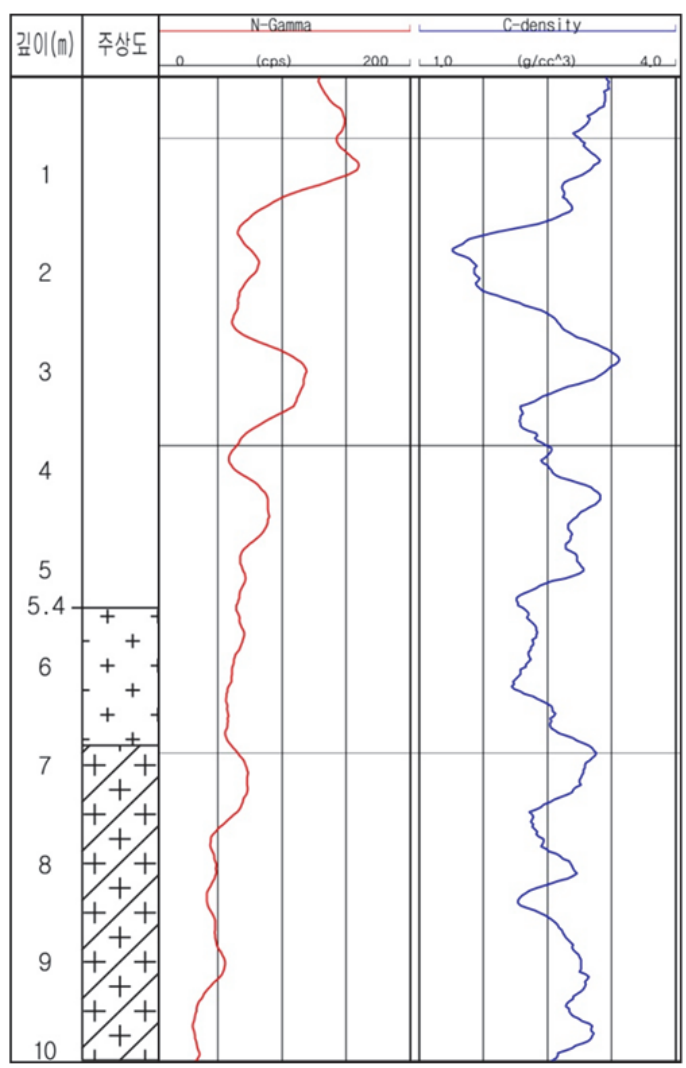

Figure 5

The measured natural gamma rays along HM-2 borehole and the estimated medium densities from the measured gamma rays

decreased at $\sim 4.5 \mathrm{~m}$ depth and was constantly maintained down to a depth of $\sim 10 \mathrm{~m}$. If groundwater flows into a borehole at a certain depth, the temperature can instantaneously decrease or increase due to the inflow of outside groundwater with a different temperature. In this study, the abrupt change in temperate gradient at about $4.5 \mathrm{~m}$ in Fig. 4 a could indicate either inflow or outflow at that depth even though the differential temperature plot in Fig. $4 \mathrm{~b}$ does not show any significant indication of flow. The electrical conductivity (EC) was also measured along the HM-2 borehole (Fig. 4c). The EC value suddenly shifts over the zone of $4.6-4.8 \mathrm{~m}$ in depth from TOC (Fig. $4 \mathrm{c}$ and $4 \mathrm{~d}$ ). This indicates that there is an inflow of groundwater with different electrical conductivity in this interval. The groundwater flow into a borehole can be interpreted from the results of these groundwater temperature and EC logs. Although the two methods can detect permeable fractures by using the difference in physical properties of the groundwater, they may be not effective in situations where the groundwater flows out of the borehole or the incoming water has the same temperature and electrical conductivity as the water in the borehole.

Figure 5 shows the estimated densities of the medium along HM-2 obtained from the gamma ray attenuation measured by the gamma-gamma log. The left trace of Fig. 5 is the natural gamma from a passive detector located away from the active gamma source and receiver set on the density probe. Density variations are large on the right-hand-side of Fig. 5 because we use a simple single detector in a 4 pi geometry probe for gamma-gamma logging that is not compensated for borehole wall diameter variations. Density values range from 1.4-3.2 g/ $\mathrm{cm}^{3}$ and the section of 1.8-1.9 $\mathrm{m}$ in depth from TOC had lower 


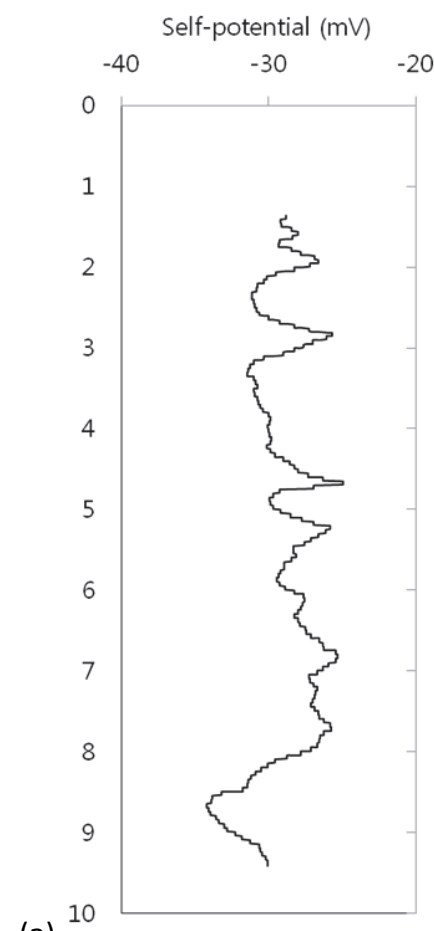

(a)

densities than those of other intervals. Low density corresponds with high porosity of a geologic medium, which can be used to identify the highly fractured zones in rock aquifers. The density measurement is affected by borehole-diameter variation, but this effect was ignored in this study because the HM-2 borehole has a nearly constant $7.6 \mathrm{~cm}$ diameter. The gamma rays detected by the density probe consist of radiation returning from the gamma source and natural background radiation emitted from the rocks penetrated by the borehole. Unless the natural gamma rays are excluded from the total gamma count in zones with relatively high gamma activity such as pegmatite, the actual medium density can be underestimated. Therefore, the 1.8-1.9 m zone, which has both lower density and low natural gamma activity, is considered a possible fractured zone.

The self-potential measurements in the HM-2 borehole are shown in Fig. 6 . The first $\sim 1 \mathrm{~m}$ of the self-potential log data are not shown here because metallic casing disturbed the measurements in that interval. Only the measurements made below the bottom of the steel casing are discussed in this study. Two significant self-potential variations are observed: one at $4.8 \mathrm{~m}$ and a second one at $8.4-8.5 \mathrm{~m}$ (Fig. 6b). At $4.8 \mathrm{~m}$ in depth the variation in self-potential signal is the greatest, consistent with the results from the BHTV and fluid electrical conductivity logs which indicated possibly permeable fractures at that depth. This variation also correlates with the temperature log which indicated an unexpected change in gradient just above $4.8 \mathrm{~m}$. Because there is no transition of rock mineral material generating a potential signal and no change of borehole-diameter in the HM-2 borehole, the $4.8 \mathrm{~m}$ depth can be considered a hydraulically-active fracture zone where groundwater having the same temperature and different electrical conductivity flows into the borehole. The other variation of self-potential at $8.4 \mathrm{~m}$ in depth is not associated with any changes in temperature, fluid electrical conductivity, and gamma-gamma logs. Although a single fracture at a similar location is detected by the acoustic borehole televiewer image log, it might be regarded as a closed fracture because there are no fracture flow indications on the temperature and EC logs. However, the $8.4 \mathrm{~m}$ depth is also a candidate for the location of a permeable fracture where the groundwater flows out from the borehole into the rock aquifer. The SP log indicates the presence of flow, and outflow would not produce any obvious indication on the EC log profile. Correlation between the SP signal and the presence of a hydraulically-active fracture is confirmed by the constant pressure injection and recovery tests.

Figure 7 summarises the candidates determined to be potentially permeable fractures using the various logging methods presented in this study. The number and location of the fractures detected by each method were generally different. These differences occur because the properties measured by each logging method are different. In the BHTV analysis, a fracture zone is identified by directly observing the presence of fractures using the scattering of an acoustic pulse. The gamma-gamma logging measures the density of fractured rock aquifers, which may be affected by the lithological heterogeneity as well as the spatial distribution of the fractures. In the HM-2 borehole, the quartz and calcite veins are sparsely located over $0.6 \sim 9.88 \mathrm{~m}$ depth from TOC, which can influence the results of the gamma-gamma log. The groundwater temperature and electrical conductivity logs are then used to evaluate the physical property of the groundwater, and can identify the permeable fractures where groundwater inflow occurs from surrounding fracture aquifers into the borehole. In this study, these measurements were performed in the natural gradient condition without an imposed artificial stress, and thus they have limitations in identifying permeable fractures where the groundwater outflow occurs from the borehole, or where active flow is only generated by pumping. Of these methods, only the self-potential log measures the electrical potential caused by the groundwater movement itself, which can be an effective tool for detecting the hydraulically-active fractures regardless of the flow direction and physical properties of the water. 


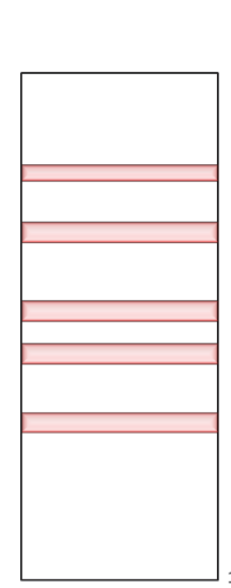

$<$ BHTV $>$
Temperature difference

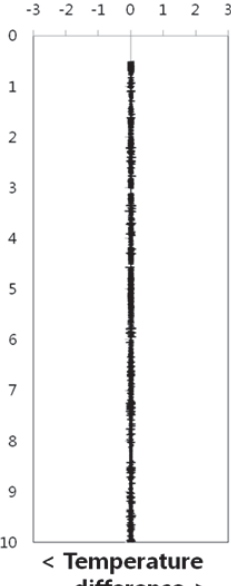

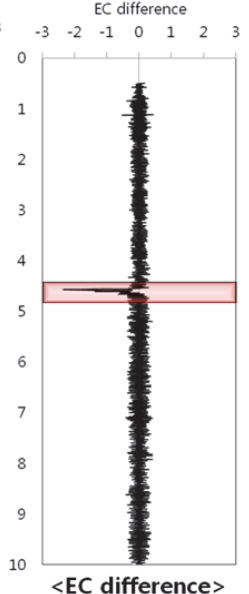

$<$ EC difference $>$

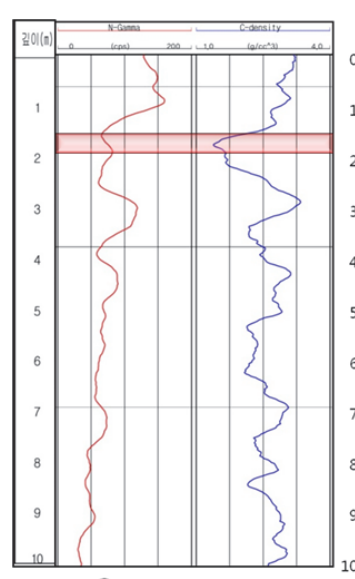

$<$ Gamma-gamma
Self-potential difference

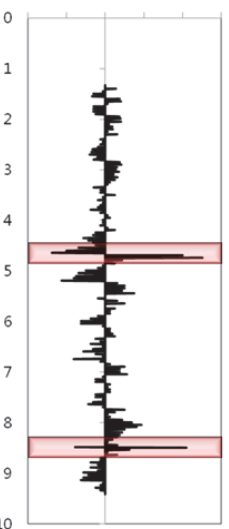

$<$ SP difference $>$
Figure 7

Identified candidates

for permeable

fractures based on

various methods

\section{Determination of the hydraulically-active fractures}

Constant pressure injection and recovery tests were conducted using a double packer system for 3 isolated zones in the HM-2 borehole, and the results were analysed using the Moye and Horner model. Table 1 shows the estimated hydraulic conductivities from the hydraulic test results. Figure 8 shows the recovery of hydraulic head as a function of test time after finishing each pressure injection. From the results of constant pressure injection and recovery tests, the hydraulic conductivity for the first zone of $1.0 \sim 4.0 \mathrm{~m}$ depth from TOC is calculated as $3.14 \times 10^{-11} \mathrm{~m} / \mathrm{s}$ using the Horner model, but cannot be measured using a Moye model because it was impossible to inject a measureable amount of water. This low value of hydraulic conductivity indicates that the depth interval of $1.0 \sim$ $4.0 \mathrm{~m}$ from TOC may be impermeable and thus this zone does not contain any permeable fractures. The low permeability of this interval can be evaluated by monitoring the recovery after increasing head in the injection interval. As shown in Fig. 8a, the increased head of the first zone in the HM-2 borehole under constant pressure injection slowly decreases during the initial recovery phase. This means that there is little permeable fracture space for the release of the increased pressure. We know from the hydraulic test results that although several apparently open fractures are observed by the BHTV logging in the $1.0 \mathrm{~m}$ to $4.0 \mathrm{~m}$ interval, they do not contribute to the groundwater flow. The possibly highly fractured zone of $1.8-1.9 \mathrm{~m}$ identified by gamma-gamma logging is also regarded as an impermeable fracture that cannot yield groundwater flow. The very small variation of SP signal in the $1.0 \sim 4.0 \mathrm{~m}$ depth interval likewise suggests that there is little groundwater flow, which corresponds to the hydraulic testing results indicating low permeability and slow recovery of pressure head.

The hydraulic conductivity of the second zone $(4.0-7.0$ $\mathrm{m})$ varies from $5.92 \times 10^{-7}$ to $6.10 \times 10^{-7} \mathrm{~m} / \mathrm{s}$, indicating that the significant groundwater flow occurs through highly permeable fractures in this section. Unlike the case of the first zone, a rapid recovery of hydraulic head is shown after initial application of pressure for the second zone (Fig. 8b). This steep slope remains steady throughout the recovery graph during total elapsed time after finishing the pressure injection, which means that the increased pressure inside the borehole is efficiently propagated through the fracture flow pathway extending away from the borehole. In other words, the fracture located in the second zone is well connected to the surrounding fracture network as well as hydraulically active in the vicinity of the
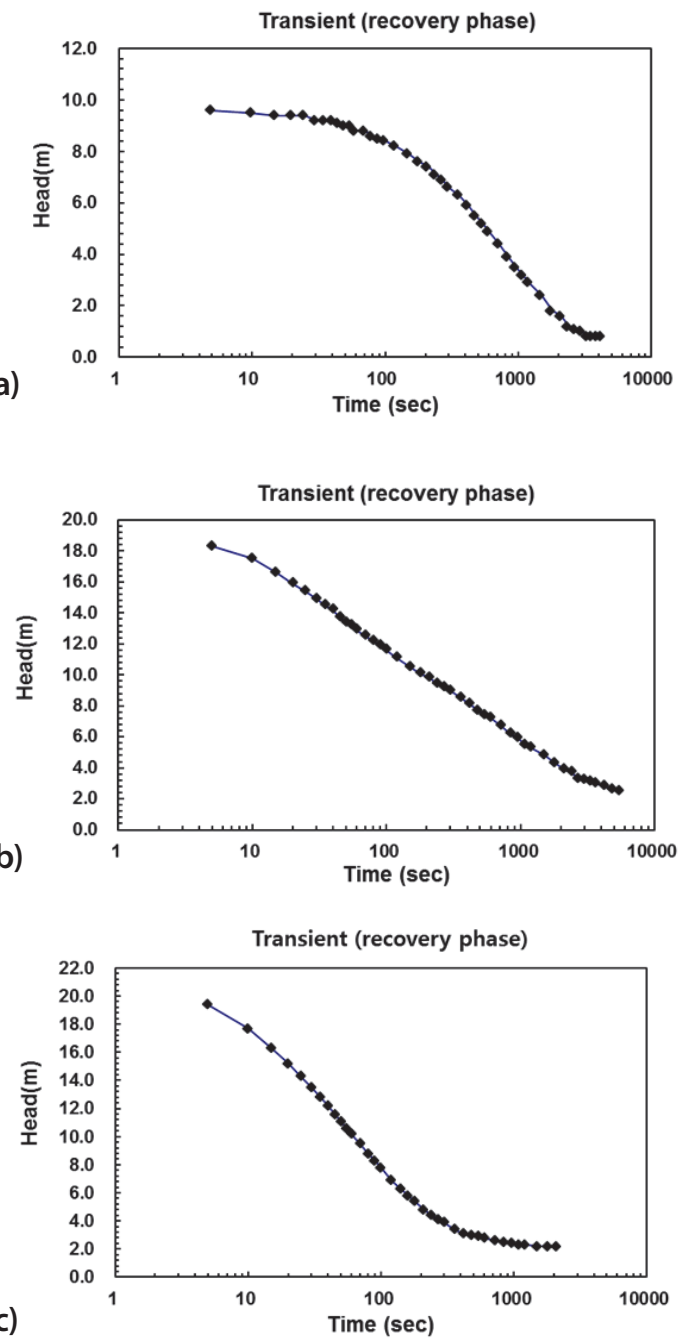

Figure 8

Recovery of hydraulic head as a function of test time after finishing the pressure injection (a) first zone: $1.0 \sim 4.0 \mathrm{~m}$ depth, (b) second zone: $4.0 \sim 7.0 \mathrm{~m}$ depth, and (c) third zone: $7.0 \sim 10.0 \mathrm{~m}$ depth

borehole. In the second zone, an apparently permeable fracture is detected at the same location by the BHTV, EC, and SP log methods, and the abrupt change in thermal gradient at this depth could also indicate flow on the temperature log. However, 
there is no detectable variation in the differential temperature and gamma-gamma measurements. Thus, the fracture located at a depth of $4.8 \mathrm{~m}$ is confirmed as a hydraulically-active fracture, where groundwater having the same temperature as the fluid column and different EC flows into the HM-2 borehole.

The hydraulic conductivities at the $7.0 \sim 10.0 \mathrm{~m}$ depth from TOC (third zone) are calculated as $4.27 \times 10^{-8}$ and $2.34 \times 10^{-8} \mathrm{~m} / \mathrm{s}$ using the Moye and Horner model, respectively. These values represent a typical permeability value for fractured-rock aquifers, which suggests that the groundwater is flowing moderately through permeable fractures as in the second zone. At the initial time stage, the fast recovery behaviour of the third zone is similar to that of the second zone (Fig. 8c). But, the recovery of pressure head becomes slower indicating reduced permeability at greater distance from the borehole when compared to the steady pressure decline of the second zone at a later time stage. The 8.5 $\mathrm{m}$ fracture zone is determined to be locally permeable and connected to the outside rock fracture system. It clearly cannot be isolated because it serves as an outlet for the flow coming down from the inflow zone at $4.8 \mathrm{~m}$. The straddle packer test data in Fig. 8 show that the water injected at section of 7-10 $\mathrm{m}$ flows into the surrounding rock formation, which confirms that the $8.5 \mathrm{~m}$ fracture zone serves as an outlet for ambient flow. In other words, this zone is not a dead-end fracture formed in the drilling process and is a hydraulically-active fracture conducting groundwater flow. In the BHTV logging, fractures interpreted as open are not observed in the $7.0 \sim 10.0 \mathrm{~m}$ interval and only several apparently closed fractures are identified. This would mean that the third zone is impermeable and cannot conduct groundwater flow, which does not correspond to the results of the hydraulic tests for this zone. No other logging methods, including the temperature, EC, and gamma-gamma, indicate permeable fractures for the $7.0 \sim 10.0 \mathrm{~m}$ zone. Only the self-potential measurement shows the apparent variation of signal at $8.4 \sim 8.5 \mathrm{~m}$ depth from TOC, which indicates the occurrence of a groundwater flow at this depth. In the third zone $(7.0 \sim 10.0 \mathrm{~m})$, a permeable fracture at $8.4 \sim 8.5 \mathrm{~m}$ in depth can be recognised as a minor permeable zone by the SP logging and its presence is verified by the constant pressure injection and recovery tests.

Thus, the permeable fracture zones identified by various logging methods and hydraulic tests consist of 2 locations with depths from TOC at $4.8 \sim 4.9 \mathrm{~m}$ and $8.4 \sim 8.5 \mathrm{~m}$ in the HM-2 borehole. Overall, the fracture characterisation by the self-potential (SP) logging method was found to show the best correlation with the hydraulic results from constant pressure injection and recovery tests, which made it possible to determine the identity of hydraulically-active fractures. Moreover, there is a positive correlation between the degree of SP variation and the hydraulic conductivity, because the intensity of potential is closely related to the speed of the flow. This indicates that the SP method can provide a semi-quantitative estimate of the hydraulic conductivity of fractures as well as the depth of those permeable fractures.

\section{DISCUSSION}

The permeable fracture located at a depth of $4.8 \mathrm{~m}$ in the HM-2 borehole is clearly an inflow zone because a shift in electrical conductivity, interpreted as the result of inflow to the borehole, is observed at that point, as shown in Fig. 4c. In contrast, the $8.5 \mathrm{~m}$ fracture is interpreted as a permeable zone where the groundwater within the borehole flows out into the rock formation, even though there is no variation in electrical conductivity and temperature at that depth, because there is a significant self-potential variation indicating groundwater movement. The bottom of the borehole cannot serve as an outflow zone, which implies that a second permeable fracture zone at $8.5 \mathrm{~m}$ must serve as an outlet point for the inflow zone identified in Fig. 4c. In this condition, the ambient flow coming down from the inflow zone at $4.8 \mathrm{~m}$ is driven by naturally-occurring hydraulic head conditions. The formation of the borehole flow inversion, the vertical ambient flow from the $4.8 \mathrm{~m}$ fracture as inlet to the $8.5 \mathrm{~m}$ fracture as outlet, can be verified by the head differences identified using the straddle packer tests in this study. The hydraulic head of the second zone, including the $4.8 \mathrm{~m}$ permeable fracture, and the third zone including the $8.5 \mathrm{~m}$ permeable fracture, are given as $11.8 \mathrm{~m}$ and $8.6 \mathrm{~m}$ under this static condition, respectively. Reference for the head values was top of casing, namely, tunnel floor. Hydraulic heads were formed at depth above TOC, tunnel floor. This head difference drives the ambient vertical flow regime, which corresponds the role of 2 permeable fractures as inflow and outflow zones as mentioned above. This hydraulic test result closely agrees with the self-potential interpretation. The ongoing borehole flow occurring between the first permeable fracture at $4.8 \mathrm{~m}$ and second permeable fracture at $8.5 \mathrm{~m}$ causes the self-potential signal between the inflow and outflow depths. However, these variations in the self-potential signal by vertical ambient flow within the borehole are much smaller than those by in- and outflows at permeable fractures, indicating that these two large self-potential responses are due to water flowing along the fracture planes and across the borehole at the inflow and outflow depths.

The streaming potential produced by flowing groundwater is not always the only component of self-potential signals. Other possible components include a redox potential from the presence of metal or metallic minerals (Naudet et al., 2004; Castermant et al., 2008; Rittgers et al., 2013) and a membrane potential from the gradient of the chemical potential of ions in the pore water of the porous material (Revil and Linde, 2006). Also, Maineult et al. (2006) evaluated the effect of clay mineralogical composition on the self-potential response through laboratory tests using various sand types. Bigalke and Grabner (1997) investigated the relation between self-potential signals and vein mineralisation of graphite. Jouniaux et al. (2009) sug gested various factors affecting the anomaly of self-potential, and reported that the self-potential signals depend on rock type or clay type and its amount. We recognise the abovementioned relationship between lithologic changes and self-potential responses. But these various lithologic effects were not considered relevant in this study because there was no transition of rock mineral material generating a potential signal along the test borehole. In this study, although we only focused on the relation between the permeability of fracture and self-potential signals in limited homogeneous granite rock, we think that it would be important to evaluate various lithologic effects on self-potential responses along boreholes located in a heterogeneous rock environment.

We also note that there are some high-resolution methods for identifying fracture flow in boreholes, such as dilution or tracer logging and heat pulse or electromagnetic flow meters, that were not used in this study. Maurice et al. $(2011 ; 2012)$ conducted the single borehole dilution logging tests under natural head conditions as a simple and cheap method of identifying vertical flow within boreholes and determining the location of in-, out- or cross-flowing fractures. Kim and Lee (2002) proposed an effective method for locating transmissive fractures using semi-analytical solutions and results from natural gradient well-to-well tracer logging tests in a fractured rock aquifer. Klepikova et al. (2011) proposed a methodology 
for using heat-pulse flow meter measurements under ambient and pumping conditions to estimate the location or hydraulic properties of fractures. Pehme et al. $(2010 ; 2014)$ measured the fine scale fluctuations of the thermal gradient and compared his results to measurements made using the heat pulse flowmeter, demonstrating superior results compared to conventional temperature profile analysis, thereby enhancing the characterisation of permeable fracture and groundwater flow in fractured rock. Paillet (2004) describes heat-pulse and electromagnetic flow meter applications in irregular or large-diameter boreholes in detecting conductive fractures, and Rosenberry and Morin (2004) investigated temporal variability of seepage flow using an electromagnetic flow meter. Future combination of these high-resolution hydrogeophysical approaches and the SP logging method could provide for even more accurate characterisation of hydraulic activity, conductivity and fracture zone geometry in fractured bedrock aquifers.

\section{CONCLUSIONS}

After identifying possibly permeable fractures with various logging methods, the results of precise hydraulic tests were used to verify the hydraulic properties of the various fractures detected by the BHTV, temperature, fluid electrical conductivity, gamma-gamma, and self-potential logs. Evaluation of the differences between the fracture sets identified by various methods suggests there are limitations to these conventional geophysical logs, except for the SP method, in detecting hydraulically-active fractures. Although the BHTV log detects most fractures located in the borehole, this method cannot evaluate the hydraulic activity of the observed fractures. The accuracy of gamma-gamma logging decreases when there is significant lithological heterogeneity. The temperature and EC logs have limitations in detecting the fractured locations where groundwater in the borehole flows out into the surrounding formation or where groundwater having the same physical property flows into the borehole. Self-potential logging can effectively detect permeable fractures through a simple procedure involving inexpensive equipment. Moreover, the SP method can provide potentially significant criteria for a quantitative characterisation of the hydraulic activity of permeable fractures, because the groundwater flow velocity is closely related to the degree of SP signal variation. Further research will focus on testing and exploring the quantitative validity of the predictions inferred from the self-potential measurements and developing comprehensive numerical models for the selfpotential response for laminar flow in fractured media.

\section{ACKNOWLEDGEMENTS}

This research was supported by the Korean Nuclear Energy R \& D Programme of the Ministry of Science and Technology, Korea, and the Radioactive Waste Management of the Korea Institute of Energy Technology Evaluation and Planning grant, funded by the Korea Government Ministry of Knowledge Economy, and the Basic Research Project of the Korea Institute of Geoscience and Mineral Resources (KIGAM), funded by the Ministry of Science, ICT and Future Planning of Korea.

\section{REFERENCES}

AL-SAIGH NH, MOHAMMED ZS and DAHHAM MS (1994)

Detection of water leakage from dams by self-potential method. Eng. Geol. 37 115-121.
ANDERSON L and JOHNSON G (1973) Application of self-potential method in search for geothermal-energy. Geophysics 38 1190-1190. BEAUHEIM RL, ROBERTS RM and AVIS JD (2004) Well testing in fractured media: flow dimensions and diagnostic plots. J. Hydraul. Res. 42 69-76.

BIGALKE J and GRABNER EW (1997) The geobattery model: a contribution to large scale electrochemistry. Electrochem. Acta $\mathbf{4 2}$ 3443-3452.

BIRCH FS (1998) Imaging the water table by filtering self-potential profiles. Ground Water 36 779-782.

CORWIN RF and HOOVER DB (1979) Self-potential method in geothermal exploration. Geophysics 44 226-245.

DOUSSAN C, JOUNIAUX L and THONY JL (2002) Variations of selfpotential and unsaturated water flow with time in sandy loam and clay loam soils. J. Hydrol. 267 173-185.

FOURNIER C (1989) Spontaneous potentials and resistivity surveys applied to hydrogeology in a volcanic area: case history of the Chaine des Puys (Puy-de-Dome), France. Geophys. Prospect. 37 647-668.

HEARST JR, NELSON PH and PAILLET FL (2000) Well Logging for Physical Properties. John Wiley \& Sons, Ltd, West Sussex. 483 pp.

HUNT CW and WORTHINGTON MH (2000) Borehole electrokinetic responses in fracture dominated hydraulically conductive zones. Geophys. Res. Lett. 27 1315-1318.

ISHIDO T and MIZUTANI H (1981) Experimental and theoretical basis of electrokinetic phenomena in rock-water systems and its applications to geophysics. J. Geophys. Res. 86 1763-1775.

ISHIDO T and PRITCHETT JW (1999) Numerical simulation of electrokinetic potentials associated with subsurface fluid flow. J. Geophys. Res. 104 15247-15259.

JARDANI A, DUPONT JP and REVIL A (2006) Self-potential signals associated with preferential groundwater flow pathways in sinkholes. J. Geophys. Res. 111 B09204.

JOUNIAUX L, MAINEULT A, NAUDET V, PESSEL M and SAILHAC $P$ (2009) Review of self-potential methods in hydrogeophysics. Comptes Rendus Geoscience 341 928-936.

KEYS WS (1990) Borehole geophysics applied to ground-water investigations. Chapter E2. In: U. S. Geological Survey Techniques of Water-Resources Investigations. Book 2. USGS, Reston. $150 \mathrm{pp}$.

KIM Y-C and LEE K-K (2002) Identification and location of transmissive fractures from analysis of tracer test data. Q. J. Eng. Geol. Hydrogeol. 35 179-188.

KLEPIKOVA MV, BORGNE TL, BOUR O and DAVY P (2011) A methodology for using borehole temperature-depth profiles under ambient, single and cross-borehole pumping conditions to estimate fracture hydraulic properties. J. Hydrol. 407 145-152.

MAINEULT A, JOUNIAUX L and BERNABE Y (2006) Influence of the mineralogical composition on the self-potential response to advection of KCL concentration fronts through sand. Geophys. Res. Lett. 33 L24311.

MALCOLM JD (1984) Borehole temperature logging for the detection of water flow. Geoexploration 22 231-243.

MAURICE LD, ATKINSON TC, BARKER JA, WILLIAMS AT and GALLAGHER AJ (2012) The nature and distribution of flowing features in a weakly karstified porous limestone aquifer. J. Hydrol. $4383-15$.

MAURICE LD, BARKER JA, ATKINSON TC, WILLIAMS AT and SMART PL (2011) Tracer methodology for identifying ambient flows in boreholes. Ground Water 49 227-238.

MOORE JR, BOLEVE A, SANDERS JW and GLASER SD (2011) Selfpotential investigation of moraine dam seepage. J. Appl. Geophys. 74 277-286.

OGILVY AA, AYED AA and BOGOSLOVSKY VA (1969) Geophysical studies of water leakages from reservoirs. Geophys. Prospect. 17 37-62.

PAILLET F (2004) Borehole flowmeter applications in irregular and large-diameter boreholes. J. Appl. Geophys. 55 39-59.

PANTHULU TV, KRISHNAIAH C and SHIRKE JM (2001) Detection of seepage paths in earth dams using self-potential and electrical resistivity methods. Eng. Geol. 59 281-295. 
PEHME PE, PARKER BL, CHERRY JA and BLOHM D (2014) Detailed measurement of the magnitude and orientation of thermal gradients in lined boreholes for characterizing groundwater flow in fractured rock. J. Hydrol. 513 101-114.

PEHME PE, PARKER BL, CHERRY JA and GREENHOUSE JP (2010) Improved resolution of ambient flow through fractured rock with temperature logs. Ground Water 48 191-205.

REVIL A, NAUDET V, NOUZARET J and PESSEL M (2003) Principles of electrography applied to self-potential electrokinetic sources and Hydrogeological applications. Water Resour. Res. 39 (5) 1114. DOI 101029/2001WR000916.

REVIL A, PEZARD PA and GLOVER P (1999) Streaming potential in porous media 1: theory of the zeta potential. J. Geophys. Res. 104 200021-200031.

RIZZO E, SUSKI B, REVIL A, STRAFACE S and TROISI S (2004) Self-potential signals associated with pumping tests experiments. J. Geophys. Res. 109 B10203.

ROSENBERRY DO and MORIN RH (2004) Use of electromagnetic seepage meter to investigate temporal variability in lake seepage. Ground Water 42 68-77.

ROZYCKI A, FONTICIELLA JMR and CUADRA A (2006) Detection and evaluation of horizontal fractures in earth dams using the selfpotential method. Eng. Geol. 82 145-153.

PRIDE SR (1994) Governing equations for the coupled electromagnetic and acoustics of porous media. Phys. Rev. B 50 15678-15696.
SCHIAVONE D and QUARTO R (1984) Self-potential prospecting in the study of water movements. Geoexploration 22 47-58.

SHARMA SP and BARANWAL VC (2005) Delineation of groundwater-bearing fracture zones in a hard rock area integrating very low frequency electromagnetic and resistivity data. J. Appl. Geophys. 57 155-166.

SILL WR (1983) Self potential modeling from primary flows. Geophysics 48 76-86.

SONG SH, SONG Y and KWON BD (2005) Application of hydrogeological and geophysical methods to delineate leakage pathways in an earth fill dam. Explor. Geophys. 36 92-96.

SUSKI B, LANDER F, BARON L, VUATAZ F-D, PHILIPPOSSIAN $F$ and HOLLIGER K (2008) Detection and characterization of hydraulically active fractures in a carbonate aquifer: results from self-potential, temperature and fluid electrical conductivity logging in the Combioula hydrothermal system in the southwestern Swiss Alps. Hydrogeol. J. 16 1319-1328.

TITTMAN J and WHAL JS (1965) The physical foundations of formation density logging (gamma-gamma). Geophysics 30 284-294.

WILLIAMS JH and CONGER RW (1990) Preliminary delineation of contaminated water-bearing fractures intersected by open-hole bedrock wells. Ground Water Monit. R. 10 (3) 118-126.

WILLIAMS JH and JOHNSON CD (2004) Acoustic and optical borehole-wall imaging for fractured-rock aquifer studies. J. Appl. Geophys. 55 (1-2) 151-159. 